\title{
A ALIENAÇÃO PARENTAL E A PERDA DO PODER FAMILIAR ${ }^{1}$
}

PARENTAL ALIENATION AND THE LOSS OF FAMILY POWER

Bruna Queiros PARANHOS ${ }^{2}$

Rosângela Aparecida Vilaça BERTONI ${ }^{3}$

ISSUE DOI: $10.21207 / 2675-0104.2018 .733$

\section{RESUMO}

Este artigo tem o objetivo de fazer uma revisão da monografia com o tema "A Alienação Parental e a Perda do Poder Familiar" no Brasil. A Alienação Parental é um fenômeno complexo que tem atingido significativamente grande parte das crianças da sociedade. Suas consequências apontam para questões de ordem psicológica, psiquiátrica e social. Têm-se apresentado teorias que partem de hipóteses e também algumas concepções que procuram identificar as possíveis causas da Alienação Parental.

Palavras chave: SAP. Alienação Parental. Síndrome da Alienação Parental.

\section{ABSTRACT}

This paper aims to review the theme of parental alienation and the loss of family power in Brazil. Parental alienation is a complex phenomenon that has significantly affected a large part of the children of society. Its consequences point to psychological, psychiatric, and social issues. It has presented theories that start from hypotheses and also some conceptions that look for to identify the possible causes of the Alienation Parental.

Keywords: SAP. Parental Alienation. Parental Alienation Syndrome.

${ }^{1} \mathrm{O}$ presente artigo sintetiza a monografia de conclusão da pesquisa, realizada para o Programa Interno de Bolsas de Iniciação Científica (PIBIC 2017-2018) da Faculdade de Direito de Franca (FDF), Franca/SP.

${ }^{2}$ Discente da Faculdade de Direito de Franca (FDF), Franca/SP. Bolsista do Programa Interno de Bolsas de Iniciação Científica (PIBIC 2017-2018).

${ }^{3}$ Possui graduação em Direito pela Faculdade de Direito de Franca (1982), mestrado em Direito Empresarial pela Universidade de Franca (2002) e Especialização em Direito Registral Imobiliário pela Universidade Esade-Espanha. Tem experiência na área de Direito, com ênfase em Direito Civil e assessoria jurídica. Advogada Militante. 
1

\section{INTRODUÇÃO}

A alienação parental pode ser definida como uma programação das reações na criança e no adolescente, levada à efeito pelo alienador (lavagem cerebral), embutindo-lhes sentimento de repulsa quanto ao outro genitor ou às demais pessoas de seu convívio, incutindo ódio e repúdio, o que impede, como consequência lógica, o bem-estar e desenvolvimento do alienado.

A Alienação Parental acontece com mais frequência quando o casal se separa e os filhos acabam sendo verdadeiras vítimas dessa patologia familiar. Geralmente, um dos genitores manipula a criança e a influência de forma que ela não mais deseje manter relação de afeto com o outro genitor, criando sentimentos de medo e angústia em relação a ele.

Não restam dúvidas de que os genitores vão sofrer com a separação. Contudo, ao invés de zelar e pouparem seus filhos do sofrimento advindo desta situação, transferem todos esses transtornos para eles, mesmo que de forma indireta. O alienador, a grande maioria das vezes, apresenta a característica de desempenhar controle absoluto sobre a vida da criança e do adolescente, interferindo na estabilidade psíquica de todos os envolvidos e atrapalhando a família das mais diversas maneiras.

É muito importante, assim, enfatizar as consequências, que a síndrome ora tratada, ocasionam ao menor. A criança ou adolescente que sofre com a Síndrome da Alienação Parental pode se tornar um adulto traumatizado, com problemas psicológicos que irão perdurar por toda a vida, conforme será demonstrado no decorrer deste artigo.

\section{A ALIENAÇÃO PARENTAL E A PERDA DO PODER FAMILIAR}

Todo indivíduo ao nascer pertence a uma família, seja ela biológica ou afetiva. O ser humano sempre precisou viver em comunidade, pois há uma necessidade de estar junto com o outro, de di vidir os momentos de felicidade e de tristeza, de contar com apoio psicológico e econômico. Assim, tem-se a ideia do quão difícil é viver isolado.

Em acepção ampla, a palavra família compreende as pessoas unidas pelo casamento, as provenientes dessa união, as que descendem de um tronco ancestral comum e as vinculadas por adoção. Em sentido 
restritivo, corresponde ao que os romanos denominavam domus, ou seja, a família compreende apenas os cônjuges e os filhos. ${ }^{4}$

A família constitui a base do Estado Democrático, sendo regulamentada pelo artigo 226 da Constituição Federal de 1988, que em seu caput dispõe: "a família é a base da sociedade, gozando de especial proteção do Estado." Portanto, a família é considerada como fundamento de toda a sociedade brasileira.

A família patriarcal, que a legislação brasileira tomou como modelo, desde o Império e durante boa parte do século $\mathrm{XX}$, ficou esquecida, em razão dos novos valores que foram introduzidos na Constituição de $1988, \operatorname{nos} \S \S 1 .^{\circ}$ a $4 .^{\circ}$ do referido art. 226 . A lei maior cuida de fazer referência a três categorias de família, quais sejam: o casamento, a união estável e o núcleo monoparental. Em razão disso, deve-se reconhecer o grande avanço que se operou, uma vez que, até então, a ordem jurídica brasileira apenas reconhecia como forma "legítima" de família aquela decorrente do casamento, de maneira que qualquer outro arranjo familiar era considerado uma vergonha para a sociedade. ${ }^{5}$

Portanto, família não é um conceito unívoco. Pode-se até afirmar, radicalizando, que a família não é uma expressão passível de conceituação, mas tão somente de descrições, ou seja, é possível reconhecer várias estruturas ou modalidades assumidas pela família através dos tempos, mas não há como atribuir elementos fixos indistintamente a todas as formas com que se apresente esse agrupamento humano.

O Direito de Família no Brasil é regrado por uma série de princípios que visam à proteção da família e principalmente à proteção do menor. Ao fazer um levantamento dos princípios que têm por fito proteger o interesse do menor, nota-se, pelo menos, cinco que prevalecem no ordenamento jurídico pátrio, porém existem muitos outros. São eles:

Princípio da afetividade: Demarcando seu conceito, é o princípio que fundamenta o Direito de Família na estabilidade das relações socioafetivas e na comunhão de vida, com primazia sobre as considerações de caráter patrimonial ou biológico. ${ }^{6}$ Esse princípio não foi proposto para tentar definir o amor, pois isso seria impossível; $O$ fato é que a afetividade tem muitas faces e aspectos e nessa complexidade tem-se a certeza de que se trata de uma forma elementar, propulsora de todas as nossas relações de

\footnotetext{
${ }^{4}$ ESPINOLA, Eduardo. A família no direito civil brasileiro. $1^{\text {a }}$ ed. Editora Bookseller. Campinas, 2001. s/v. p. 09/11

${ }^{5}$ LÔBO, Paulo. Direito Civil: Famílias. $2^{a}$ ed. Editora Saraiva. São Paulo, 2009. s/v. p.1

${ }^{6}$ Ibidem, p.47
} 
vida, pois afeto é a relação de cuidado, amor, é o carinho que se apresenta nas relações familiares.

Princípio da dignidade da pessoa humana: esse é o princípio maior, já que a dignidade da pessoa humana é essencial a todas as pessoas. É outro princípio que é de difícil conceituação, uma vez que não há definição concreta para a sua essência; Kant procurou distinguir aquilo que tem um preço, seja pecuniário, seja estimativo, do que é dotado de dignidade, a saber, do que é inestimável, do que é indisponível, do que não pode ser objeto de troca. Kant diz que "No reino dos fins tudo tem ou um preço ou uma dignidade. Quando uma coisa tem um preço, pode-se pôr em vez dela qualquer outra como equivalente. Mas, quando uma coisa está acima de todo preço, e, portanto, não permite equivalência, então tem ela dignidade". Portanto, todo ato em que se coisifique a pessoa humana é uma afronta ao princípio da dignidade, assim como aquele que a equipare a um objeto ou a uma coisa disponível. Deve haver respeito no âmbito da comunidade entre os seres humanos. ${ }^{7}$

Princípio da plena proteção das crianças e adolescentes: as crianças e adolescentes gozam, no seio da família, de plena proteção e prioridade absoluta quanto ao tratamento que lhe é proporcionado por sua família ou por quem exerça cuidado sobre ela. Isso significa que, em respeito à função social desempenhada pela família, os pais devem proporcionar aos filhos o acesso adequado à saúde, educação, lazer, alimentação, vestuário, etc. A inobservância de tais mandamentos pode gerar responsabilização criminal e civil.

Princípio da convivência familiar: pais e filhos, por esse princípio, devem permanecer juntos. A relação afetiva mais duradoura entre as pessoas que compõem um mesmo grupo familiar é a convivência, seja por virtude de laços parentescos ou não. A convivência é o ninho no qual as pessoas se sentem solidariamente acolhidas e protegidas, especialmente as crianças. A convivência familiar ultrapassa o exercício do poder familiar. Assim, ainda que os pais estejam separados, o filho menor tem direito de relacionar-se com cada um deles, não podendo o guardião impedir o acesso da criança ao outro genitor, se advinda de restrições indevidas. $\mathrm{O}$ ambiente familiar é o responsável por formar um ser humano que sinta que a vida vale a pena ser vivida. Os problemas psíquicos seriam, portanto, resultados de falhas graves nas etapas iniciais do desenvolvimento. ${ }^{8}$

${ }^{7}$ LÔBO, Paulo. Direito Civil: Famílias. $2^{a}$ ed. Editora Saraiva. São Paulo, 2009. s/v. p.37

${ }^{8}$ LÔBO, Paulo. Direito Civil: Famílias. $2^{a}$ ed. Editora Saraiva. São Paulo, 2009. s/v. p.52 
Princípio do melhor interesse da criança: esse princípio significa que a criança e o adolescente devem ter seus interesses tratados com prioridade, pelo Estado, pela sociedade e pela a família, tanto na elaboração quanto na aplicação dos direitos que lhe digam respeito, notadamente nas relações familiares, como pessoa em desenvolvimento e dotada de dignidade. O pátrio poder existia em função do pai, já o poder familiar existe em função e para o interesse do filho. Nas separações dos pais, o interesse da criança era secundário ou irrelevante, contudo, hoje, qualquer decisão deve ser tomada considerando seu melhor interesse. ${ }^{9}$

A convivência em família é complexa, porque cada ser humano tem o seu modo de agir, de pensar, cada um tem seu temperamento, idade e composição genética. Por esses motivos, os conflitos estão presentes na maioria das famílias, pelo próprio fato de que cada pessoa tem suas próprias características e, por mais que convivam juntas, nem sempre terão a mesma opinião e a mesma vontade. Sendo assim, a vivência familiar é marcada por altos e baixos, brigas e reconciliações, o que acaba atrapalhando o bom convívio entre os membros.

No entanto, por se tratar de conflitos familiares, deve-se tomar cuidado para que não sejam rompidos os laços afetivos. Pois, dependendo da natureza ou dos motivos acirrados, podem conduzir o casal à separação, cuja questão pode se tornar ainda mais complexa quando existem filhos envolvidos.

O divórcio dos pais é um processo doloroso para os filhos e para diminuir esse trauma é importante que seja mantido o ambiente familiar da melhor maneira possível, bem como que os pais conduzam este momento tormentoso com zelo, pois quanto mais conflito existir neste momento do divórcio, mais doloroso será para os filhos e isso pode trazer sérios danos psicológicos para as crianças e adolescentes, capaz de torná-los adultos com sérios problemas psíquicos.

\section{O PODER FAMILIAR}

Carlos Roberto Gonçalves, em sua obra, ensina que o poder familiar é representado por um conjunto de regras que engloba direitos e

\footnotetext{
${ }^{9}$ Ibidem, p.54.
} 
deveres atribuídos aos pais, no tocante à pessoa e aos bens dos filhos menores. ${ }^{10}$

O Código Civil de 2002 (Código atualmente vigente), em seu artigo 1.631, dispõe que: "Durante o casamento e a união estável, compete o poder familiar aos pais; na falta ou impedimento de um deles, o outro o exercerá com exclusividade. Parágrafo único: Divergindo os pais quanto ao exercício do poder familiar, é assegurado a qualquer deles recorrer ao juiz para solução do desacordo".

O poder familiar é irrenunciável, intransferível, inalienável e imprescindível. Pertence a ambos os pais, desde o nascimento até os 18 anos do filho, ou até a emancipação deste. ${ }^{11}$

A primeira parte do artigo 229 da Carta Magna diz que "Os pais têm o dever de assistir, criar e educar os filhos menores".

Simultaneamente, o Estatuto da Criança e do Adolescente, em seu artigo 22 dispõe que: "Aos pais incumbe o dever de sustento, guarda e educação dos filhos menores, cabendo-lhes ainda, no interesse destes, a obrigação de cumprir e fazer cumprir as determinações judiciais. Parágrafo único: A mãe e o pai, ou os responsáveis, têm direitos iguais e deveres e responsabilidades compartilhadas no cuidado e na educação da criança, devendo ser resguardado o direito de transmissão familiar de suas crenças e culturas, assegurados os direitos da criança estabelecidos nesta Lei”.

A atual doutrina, da qual fazem parte Maria Berenice Dias, Paulo Lôbo e Rolf Madaleno, insere a responsabilidade afetiva como uma obrigação dos pais, exercida por meio da convivência familiar, despontando, inclusive, a responsabilidade civil para o genitor que descumprir esse dever de cuidar, no amplo sentido da palavra.

Assim, o não cumprimento do dever de alimentos, por exemplo, configura abandono material, tipificado tanto pelo Código Penal, em seu artigo 244, quanto pelo Estatuto da Criança e do Adolescente, em seu artigo 249.

Ademais, os pais respondem pelos atos praticados pelos filhos enquanto menores, com a chamada responsabilidade civil objetiva por ato de terceiro (art. 932, I, do Código Civil), que deve abranger o cônjuge não guardião, no caso de pais separados, uma vez que ele não possui a guarda,

\footnotetext{
${ }^{10}$ GONÇALVES, Carlos Roberto. Direito Civil Brasileiro. 14 ${ }^{\text {a }}$ ed. Editora Saraiva. São Paulo, 2017. Volume 6. p. 415.

${ }^{11}$ MADALENO, Ana Carolina Carpes; MADALENO, Rolf. Síndrome da Alienação Parental: Importância da Detecção Aspectos Legais e Processuais. $4^{a}$ edição. Editora Forense. Rio de Janeiro, 2013. s/v. p. 27.
} 
mas não perde o direito de ter filho em sua companhia ou, ao menos, sob sua autoridade. ${ }^{12}$

Como o poder familiar é um dever dos pais em relação aos filhos, cabe ao Estado fiscalizar sua execução, podendo aplicar sanções como a suspensão ou a destituição do poder familiar aos genitores faltosos. Mas isso não faz cessar o direito do menor de ser credor de alimentos, ainda que um ou ambos os pais não detenham a guarda, salvo no caso de adoção, pois quando a criança é adotada a outra família assume esse encargo.

A suspensão do poder familiar é imposta nas infrações menos graves, que estão mencionadas no artigo 1.637 do Código Civil, que assim dispõe: "se o pai, ou a mãe, abusar de sua autoridade, faltando aos deveres a eles inerentes ou arruinando os bens dos filhos, cabe ao juiz, requerendo algum parente, ou o Ministério Público, adotar a medida que lhe pareça reclamada pela segurança do menor e seus haveres, até suspendendo o poder familiar, quando convenha. Parágrafo único. Suspende-se igualmente o exercício do poder familiar ao pai ou à mãe condenados por sentença irrecorrível, em virtude de crime cuja pena exceda a dois anos de prisão".

A suspensão é temporária, tendo em vista que terminada a causa que a motivou, volta a mãe, ou o pai, que foram temporariamente impedidos, a exercer o poder familiar. A suspensão também pode se referir unicamente a determinado filho.

O Estatuto da Criança e do Adolescente, em seu artigo 23, dispõe que a falta ou carência de recursos materiais não constitui, por si só, motivo suficiente para a suspensão ou a perda do poder familiar.

Em seu livro, Paulo Luiz Netto Lôbo ressalta que:

A suspensão pode ser sempre revista, quando superados os fatores
que a provocaram. No interesse dos filhos e da convivência
familiar, apenas deve ser adotada pelo juiz quando outra medida
não possa produzir o efeito desejado, no interesse da segurança do
menor e de seus haveres. Cessada a causa que levou á suspensão, o
impedido volta a exercer o poder familiar plenamente ou segundo
restrições determinadas pelo juiz. ${ }^{13}$

A extinção do poder familiar ocorre por fatos naturais, de pleno direito, ou por decisão judicial. O artigo 1.635, do Código Civil menciona

12 MAdAlenO, Ana Carolina Carpes; MADALENO, Rolf. Síndrome da Alienação Parental: Importância da Detecção Aspectos Legais e Processuais. $4^{\mathrm{a}}$ edição. Editora Forense. Rio de Janeiro, 2013. s/v. p.33.

${ }^{13}$ DIAS, Maria Berenice. Direito de Família e o Novo Código Civil. $4^{\mathrm{a}}$ ed. Editora Del Rey. Belo Horizonte, 2005. s/v. p.16. 
as causas de extinção que são: morte dos pais ou do filho, emancipação, maioridade, adoção e decisão judicial na forma do artigo 1.638. O rol do artigo 1.635 é taxativo, não sendo admitido o reconhecimento de nenhuma outra causa de extinção por envolverem a restrição de direitos fundamentais.

A perda do poder familiar decorre de faltas graves, que configuram, inclusive, ilícitos penais, as quais estão especificadas no artigo 1.638 do Código Civil, que assim dispõe: "Perderá por ato judicial o poder familiar o pai ou a mãe que: I- castigar imoderadamente o filho (configura crime de maus-tratos); II- deixar o filho em abandono (configura crime de abandono material e intelectual); III- praticar atos contrários à moral e aos bons costumes (crimes de natureza sexual contra os filhos ou conduta inconveniente, como uso de entorpecentes ou entrega da mãe a prostituição); IV - incidir, reiteradamente, nas faltas previstas no artigo antecedente; V - entregar de forma irregular o filho a terceiros para fins de adoção.”

Embora a lei utilize os termos "perda e extinção", a perda é uma sanção de maior alcance, correspondente à infringência de um dever mais relevante, tendo como consequência a extinção. "A privação do exercício do poder familiar deve ser encarada de modo excepcional, quando não houver qualquer possibilidade de recomposição da unidade familiar, o que recomenda estudo psicossocial". ${ }^{14}$

Acontecendo um dos casos do artigo 1.638 do Código Civil, o Estatuto da Criança e do Adolescente dispõe que o Judiciário deve ser provocado pelo Ministério Público ou pelo interessado por meio de um advogado, que apresentará uma petição inicial que exponha o caso, ao passo que o juiz decidirá pensando sempre no bem-estar e no melhor interesse da criança e do adolescente.

A Alienação Parental e o Poder Familiar são Institutos correlatos, conforme ensina Maria Berenice Dias:

Esse tema começa a despertar a atenção, pois é prática que vem sendo utilizada de forma recorrente e irresponsável. Muitas vezes, quando da ruptura da vida conjugal, um dos cônjuges não consegue elaborar adequadamente o luto da separação e o sentimento de rejeição, de traição, faz surgir um desejo de vingança: desencadeia um processo de destruição, de desmoralização, de descrédito do exparceiro. Nada mais do que uma "lavagem cerebral" feita pelo

\footnotetext{
${ }^{14}$ MADAlEnO, Ana Carolina Carpes; MADALENO, Rolf. Síndrome da Alienação Parental: Importância da Detecção Aspectos Legais e Processuais. $4^{\mathrm{a}}$ edição. Editora Forense. Rio de Janeiro, 2013. s/v. p.2
} 
genitor alienador no filho, de modo a denegrir a imagem do outro genitor, narrando maliciosamente fatos que não ocorreram e não aconteceram conforme a descrição dada pelo alienador. Assim, o infante passa aos poucos a se convencer da versão que lhe foi implantada, gerando a nítida sensação de que essas lembranças de fato aconteceram. Isso gera uma contradição de sentimentos e destruição do vínculo entre o genitor e o filho. Restando órfão do genitor alienado, acaba se identificando com o genitor patológico, passando a aceitar como verdadeiro tudo que lhe é informado. ${ }^{15}$

Para a jurisprudência, a Alienação Parental pode levar à perda da guarda pelo genitor, bem como provocar discussão a respeito da destituição do poder familiar. Ilustrando, segue a ementa:

Destituição do poder familiar. Abuso sexual. Síndrome da Alienação Parental. Estando as visitas do genitor à filha sendo realizadas junto a serviço especializado, não há justificativa para que se proceda a destituição do poder familiar. A denúncia de abuso sexual levada a efeito pela genitora não está em evidência, havendo a possibilidade de se estar frente à hipótese da chamada síndrome da alienação parental. Negado provimento" (TJSP, Agravo de Instrumento 70015224140, $7^{\mathrm{a}}$ Câmara de Direito Privado, Rel. Maria Berenice Dias, decisão de 12.06.2006). ${ }^{16}$

Com toda essa evolução da jurisprudência e da doutrina, foi promulgada a Lei n. ${ }^{\circ} 12.318$ de 2010 , conhecida como Lei da Alienação Parental. O comando legal define o fundamento do Instituto e exemplifica algumas situações concretas de sua ocorrência. $\mathrm{O}$ artigo $3 .^{\circ}$ da referida lei dispõe que: "a prática de ato de alienação parental fere direito fundamental da criança e do adolescente de convivência familiar saudável, prejudica a realização de afeto nas relações com genitor e com o grupo familiar, constitui abuso moral contra a criança ou o adolescente e descumprimento dos deveres inerentes à autoridade parental ou decorrentes de tutela e guarda".

Ou seja, há consequência direta para o poder familiar, vez que a alienação parental pode gerar a responsabilidade civil do alienador por abuso de direito (art. 187 do CC).

Averiguado indício de ato de Alienação Parental, serão determinadas as medidas cabíveis, a requerimento ou de ofício, em qualquer momento processual, em ação autônoma ou incidentalmente, sendo que o processo terá tramitação prioritária, e o juiz determinará, com

${ }^{15}$ DIAS, Maria Berenice. Manual de Direito das Famílias. $5^{\text {a }}$ ed. Editora RT. São Paulo, 2009. s/v. p. 418.

${ }_{16}$ TARTUCE, Flávio. Manual de Direito Civil. $2^{\mathrm{a}}$ ed. Editora Método. São Paulo, 2012. Volume Único. p. 1196. 
urgência, ouvido o Ministério Público, as medidas provisórias necessárias para a preservação da integridade psicológica da criança ou do adolescente (art. 4. ${ }^{\circ}$ da Lei 12.318/2010).

Quanto à guarda, deve ser dada preferência ao genitor que viabiliza a efetiva convivência da criança ou adolescente com o outro genitor, nas hipóteses em que seja inviável a guarda compartilhada (artigo 7. ${ }^{\circ}$ da Lei 12.318/10). Desse modo, a solução passa a ser a guarda unilateral, quebrando-se a regra da guarda compartilhada, constante dos arts. 1.583 e 1.584 do Código Civil.

\section{DA ALIENAÇÃO PARENTAL}

A alienação parental é o ato de difamar a imagem de um dos pais perante os filhos. Ocorre geralmente no momento da separação do casal e pode ser praticada por um dos pais, pelos dois ou até mesmo por terceiros, como tios, avós, padrinhos, causando o afastamento entre filho e um dos genitores. Com a separação, os pais têm decisões muito importantes e difíceis a serem tomadas e uma delas - que causa mais desavenças é com quem ficará a guarda da criança, a partir da qual inicia-se o problema em tela, pois o genitor que não fica com a guarda pode se tornar alienador, que manipula o menor nos momentos de visita, embora o alienador também possa ser aquele que detém o direito a guarda. A prática da Alienação Parental pode ocorrer ainda quando o casal vive sob o mesmo teto.

A Alienação Parental nem sempre se faz através de atos voluntários e conscientes. Pode ocorrer situações em que o alienador se isenta, por exemplo, de interferir nas visitas do outro genitor, mostrandose ostensivamente resignado à força da lei e esquivando-se de falar mal do outro, chegando a ponto de dizer palavras de incentivo ao filho. Mas tal conduta se expressa de modos não verbais e que são facilmente decodificados pela criança ou pelo adolescente.

Como consequência da Alienação Parental, há a Síndrome da Alienação Parental. A primeira pessoa a conceituar esse termo foi Richard Gardner. A síndrome tem início a partir das disputas judiciais pela guarda dos filhos. Os processos de separação geram nos filhos sentimentos de angústia, abandono, rejeição e medo de um dos genitores não gostar mais deles. O genitor alienador começa a programar a criança para que ela odeie e repudie, sem justificativa, o outro genitor, com o objetivo de obstruir, impedir ou, muitas vezes, destruir o vínculo da criança com o outro. A 
Síndrome da Alienação Parental é uma lavagem cerebral com contribuições da própria criança. A criança vai aceitando com o tempo que as falsas implantações são verdades e por consequência vai se afastando do outro genitor.

A síndrome em questão não é difícil de ser identificada. Um dos primeiros sintomas é quando a criança absorve tudo o que o genitor alienando fala e passa a atacar o genitor alienado, com injúrias, agressões, interrupção da convivência, embora intimamente ame esse genitor. Para esse genitor alienado é muito difícil ver o seu filho se dirigindo com palavras de ódio - o que gera o afastamento da criança de sua convivência.

$\mathrm{O}$ genitor alienante pode, no decorrer do tempo, dar demonstrações de vários transtornos psicológicos, dentre os diversos transtornos e características do genitor alienante, sendo os mais comuns: a intolerância, perfeccionismo e o desejo de exclusividade no vínculo.

As condutas expressas levadas a cabo pelo genitor alienante no processo de implementação da SAP, começam com simples gestos, como o de não passar o telefone aos filhos quando o outro genitor liga, denigrir a imagem do outro genitor, não informar ao genitor alienado sobre as atividades escolares do filho, organizar tarefas no dia de visitas do outro genitor, pedir para que o filho escolha entre os dois pais. Essas são algumas das diversas formas de começar a implantação da SAP, com o objetivo de alienar os filhos do precioso contato com seu outro genitor.

\section{CONSEQUÊNCIAS PARA AS CRIANÇAS ALIENADAS}

É de suma importância o modo como os pais enfrentam o período de divórcio ou dissolução de sua união, a fim de verificar a maneira como seus filhos se comportarão, uma vez que isso pode ocasionar danos que apenas serão constatados quando os filhos tiverem suas próprias relações pessoais.

É evidente que, quando instalada a Síndrome da Alienação Parental, os danos psíquicos e comportamentais na relação entre a criança e o genitor alienado são devastadores. Para a criança, de uma hora para outra, aquele genitor que ela tanto amava e tinha admiração se torna um estranho. Depois do dano psicológico sofrido por ela, a principal consequência averiguada é a violação ao princípio do convívio familiar. A convivência em família e a visitação são direitos constitucionais e os filhos devem estar em constante convívio com ambos os pais. Porém, o genitor 
alienante faz com que esse convívio se torne cada dia mais difícil, de forma que eventualmente a criança vai perdendo, aos poucos, o contato com o genitor alienado, que será tido por ela como um estranho.

Os danos causados pela Síndrome da Alienação parental, se não forem tratados ou caso não identificados, podem durar a vida toda, influenciando a personalidade da criança e em sua formação psicológica, gerando sentimentos ruins ante o alienado, de forma que isso pode acarretar consequências em sua relação com a sociedade como um todo.

Quando é identificada a Síndrome, o principal tratamento a ser adotado é a terapia para todos os envolvidos na situação, isto é, o genitor alienante, o genitor alienado e, obviamente, a criança atingida. A terapia será um tratamento psicológico que irá durar um longo período, tendo por objetivo trabalhar as relações interpessoais e familiares que estão rompidas, para que se instaure uma nova oportunidade de convivência sadia.

Cabe ao Judiciário, também, analisado o caso concreto e o melhor interesse da criança, efetuar a modificação da guarda do menor, passando ao genitor alienado a titularidade da guarda, conferindo-se ao outro genitor o direito de visitas supervisionadas.

As consequências da Síndrome da Alienação Parental aparecerão futuramente, quando a vítima já for adolescente ou adulto e possuir pleno entendimento dos acontecimentos. Em tal momento, passará a não respeitar o seu guardião, em razão da alienação por ele exercida, pois carregará remorso e culpa pela injustiça realizada com o outro genitor.

Esses sentimentos internalizados, se não trabalhados por psicólogos, podem levar a atitudes extremas como, por exemplo, o envolvimento com drogas, crises depressivas e suicídio. O maior problema ocorre quando o alienado não encontra o paradeiro do genitor (vitimado), não podendo realizar uma reversão da situação pendente e de seus sentimentos. Faz-se importante, portanto, o reconhecimento dos atos alienatórios antes que a síndrome se fixe na criança ou no adolescente. ${ }^{17}$

\footnotetext{
${ }^{17}$ MEIRELLES, Fernanda. Consequências da Síndrome de Alienação Parental (SAP). Disponível em: <https://femorettimeirelles.jusbrasil.com.br/artigos/120002923/consequencias-da-sindrome-dealienacao-parental-sap>. Acesso em: 23 jul. 2018.
} 


\section{CONSIDERAÇÕES FINAIS}

O tema abordado não é fenômeno social raro. O objetivo do artigo foi buscar a compreensão do assunto devido à alta ocorrência em sociedade. A maioria dos casais que têm filhos durante o relacionamento e logo depois se separaram estão sujeitos a sofrer esse tipo de problema. A Síndrome da Alienação Parental deve ser identificada o quanto antes, para que possa haver possibilidade de reversão.

É de extrema importância ressaltar que todos sofrem com a Síndrome da Alienação Parental, o genitor alienador, o genitor alienado e os menores. O menor que sofre com a síndrome deve ser tratado com mais cuidado e atenção, pois as sequelas que a síndrome deixa na criança podem segui-la durante toda a vida, influenciando o seu desenvolvimento psicológico.

Por fim, vale dizer que o Estado não deve se omitir perante a uma situação tão grave que destrói lares, afasta crianças de seu pais e as afeta diretamente e intensivamente por toda sua vida. Se a síndrome não for tratada como deve, milhares de crianças vão se tornar adultos traumatizados. A cautela quanto à ocorrência de situações como essas ocorre em benefício do bem-estar e melhor interesse da parcela mais vulnerável da população: crianças e adolescentes.

\section{REFERÊNCIAS BIBLIOGRÁFICAS}

DIAS, Maria Berenice. Direito de Família e o Novo Código Civil. $4^{\mathrm{a}}$ ed. Editora Del Rey. Belo Horizonte, 2005. s/v.

DIAS, Maria Berenice. Manual de Direito das Famílias. $5^{\text {a }}$ ed. Editora RT. São Paulo, 2009. s/v.

ESPÍNOLA, Eduardo. A família no direito civil brasileiro. $1^{\mathrm{a}}$ ed. Editora Bookseller. Campinas, 2001. s/v.

GONÇALVES, Carlos Roberto. Direito Civil Brasileiro. 14 ${ }^{\text {a }}$ ed. Editora Saraiva. São Paulo, 2017. Volume 6.

LÔBO, Paulo. Direito Civil: Famílias. $2^{a}$ ed. Editora Saraiva. São Paulo, 2009. s/v. MADALENO, Ana Carolina Carpes; MADALENO, Rolf. Síndrome da Alienação Parental: Importância da Detecção Aspectos Legais e Processuais. 4 edição. Editora Forense. Rio de Janeiro, 2013. s/v.

MEIRELLES, Fernanda. Consequências da Síndrome de Alienação Parental (SAP). Disponível em: <https://femorettimeirelles.jusbrasil.com.br/artigos/120002923/consequencias-da-sindrome-dealienacao-parental-sap>. Acesso em: 23 jul. 2018. 
TARTUCE, Flávio. Manual de Direito Civil. 2ª ed. Editora Método. São Paulo, 2012. Volume Único. 